\title{
A RESPONSABILIDADE AMBIENTAL-TRABALHISTA DECORRENTE DA UTILIZAÇÃO DE AGROTÓXICOS
}

\section{THE ENVIRONMENTAL-LABOR RESPONSIBILITY RESULTING FROM THE USE OF PESTICIDES}

\author{
${ }^{1}$ Cristiano Lourenço Rodrigues \\ ${ }^{2}$ Rafael Veríssimo Siquerolo
}

\section{RESUMO}

O presente artigo trata de um assunto pouco debatido na doutrina trabalhista, a temática dos agrotóxicos e a responsabilidade socioambiental dos empregadores pelos riscos e agravos à saúde do trabalhador, notadamente o rual. Nada obstante os estudos amplos e profícuos sobre a questão dos agrotóxicos, em especial no âmbito de outras ciências, não há muitos estudos jurídicos focados na proteção do trabalhador. O meio ambiente do trabalho é direito humano fundamental (artigo $7^{\circ}$, inciso XXII, e artigo 200, inciso VIII, da Constituição da República) e sua higidez surge como dever contratual do empregador. Os estudos sobre a realidade da questão são demonstrativos da situação de risco a que são submetidos os trabalhadores e da ausência de proteção à saúde e segurança das pessoas que manuseiam estas substâncias tóxicas. Somente o empoderamento do conhecimento científico, em todos os níveis, incluído o jurídico, poderá mobilizar a sociedade para combater os problemas.

Palavras-chave: Trabalhador, Agrotóxicos, Socioambientalismo, Proteção

\begin{abstract}
This article deals with a subject little discussed in the labor doctrine, the issue of pesticides and environmental responsibility of employers for the risks and harm to workers' health, particularly the rural. Nonetheless the broad and fruitful studies on the issue of pesticides, particularly in the context of other sciences, there are not many legal studies focused on worker protection. The working environment is a fundamental human right (article 7, paragraph XXII, and article 200, section VIII, of the Constitution of the Republic) and their healthiness comes as a contractual duty of the employer. Studies on the reality of the issue are statements of risk they are subjected to the workers and the absence of health protection and safety of persons handling these toxic substances. Only the empowerment of scientific knowledge, at all levels, including legal, can mobilize society to combat the problems.
\end{abstract}

Keywords/Palabras-claves/Mots-clés: Worker, Pesticides, Socioenvironmentalism, Protection

\footnotetext{
${ }^{1}$ Mestrando em Direito Negocial pela Universidade Estadual de Londrina - UEL, Paraná (Brasil). Professor de Direito Processual do Trabalho na Instituição Toledo de Ensino de Presidente Prudente (Brasil). E-mail: cdrlourenco@terra.com.br

${ }^{2}$ Mestrando em Direito Negocial, pela Universidade Estadual de Londrina - UEL, Paraná (Brasil). Professor de Direito Processual Civil na Faculdade Metropolitana de Maringá - FAMMA, Paraná (Brasil). E-mail: verissimo@vv.adv.br
} 


\section{INTRODUÇÃO}

Compreendido o direito ao meio ambiente ecologicamente equilibrado como direito humano fundamental, a questão dos agrotóxicos se mostra tormentosa, porque a eliminação dos riscos atinentes ao uso das substâncias tóxicas é improvável e até mesmo impossível.

Os trabalhadores, notadamente os rurais, encarregados de manipular os agrotóxicos, sofrem com a precarização das condições de trabalho e não são tutelados juridicamente. Desprotegidos sob o aspecto jurídico, tornam-se vítimas de uma lógica mercadológica que lhes nega o direito humano fundamental de sadia qualidade de vida.

Não há dúvida de que o uso dos agrotóxicos causa contaminação. Trata-se de uma atividade danosa permitida e que encontra regulamentação em lei. Deliberadamente e sob o abrigo da permissão estatal são utilizadas as substâncias venenosas, cientes os usuários do poder destrutivo em relação ao meio ambiente natural e ao meio ambiente do trabalho.

De acordo com Eduardo Garcia Garcia e José Prado Alves Filho (2005, p. 10), o primeiro Pesquisador da Coordenação de Saúde no Trabalho da FUNDACENTRO, o segundo Pesquisador da Coordenação de Segurança no Processo de Trabalho da FUNDACENTRO, dados da Organização Mundial da Saúde (OMS) estimavam, em 1990, que o uso de agrotóxicos no mundo era da ordem de 3 milhões de toneladas/ano, expondo, através do trabalho agrícola, mais de 500 milhões de pessoas. Também estimavam que os casos anuais de intoxicações agudas não intencionais fossem de 1 milhão, com 20 mil mortes, sendo a exposição ocupacional responsável por 70\% desses casos de intoxicação. Embora reconhecendo que os efeitos crônicos são mais difíceis de serem avaliados, foram estimados pela OMS $700 \mathrm{mil}$ casos/ano de dermatoses, 37 mil casos/ano de câncer em países em desenvolvimento e 25 mil casos/ano de sequelas neurocomportamentais persistentes ocasionadas por intoxicações ocupacionais por compostos organofosforados. Quinze anos depois, em 2005, a OMS, em conjunto com a Organização Internacional do Trabalho (OIT), passou a estimar em 7 milhões os casos de intoxicações agudas e de longo termo e 70 mil óbitos provocados por agrotóxicos anualmente no mundo, sobretudo nos países em desenvolvimento.

Em meio a dados tão assustadores, a situação dos trabalhadores, pouco divulgada na grande mídia, é extremamente delicada e preocupante. No estudo desenvolvido pelos pesquisadores da FUNDACENTRO acima citados, há menção à situação do trabalhador rural perante um quadro de precarização das condições de trabalho e ausência de uma cultura trabalhista preventiva, em que, abandonado à própria sorte, subestima os efeitos nocivos da 
toxicidade em seus organismos e deixa a cautela necessária de lado, naquilo que os autores denominam senso de imunidade subjetiva e ideologia ocupacional defensiva (GARCIA; ALVES FILHO, 2005, p. 23):

\begin{abstract}
O senso de imunidade subjetiva, ou a minimização da probabilidade de que algo negativo (o acidente) possa ocorrer no ambiente de trabalho, seria uma dessas estratégias que os trabalhadores desenvolvem a fim de fazer frente ao problema do medo no trabalho sob condições de risco e com alta incerteza. Outros mecanismos poderiam ser identificados configurando, assim, uma espécie de ideologia ocupacional defensiva, a qual buscaria na negação do perigo (embora conhecido) a possibilidade de se continuar realizando o trabalho, sem desencadear uma ruptura das defesas psíquicas construídas socialmente para superar o medo no trabalho.
\end{abstract}

Há que compreender como as normas jurídicas constitucionais que integram o ordenamento jurídico pátrio elegem o meio ambiente do trabalho como direito humano fundamental e estabelecem o dever de assegurar a integridade psicofísica dos trabalhadores.

Outrossim, conhecer as normas legais infraconstitucionais que regem a temática e os mecanismos de controle dos riscos mostra-se fundamental para entender como a sociedade e vários legitimados (associações, sindicatos, Ministério Público) podem combater o problema. Discutir a efetividade das normas jurídicas protetivas implica refletir sobre diversos fatores de ordem extrajurídica. As alternativas para o controle dos riscos causados pelos agrotóxicos extrapolam o aspecto puramente formal das regras legais.

Uma vez compreendidos tais aspectos, o trabalho buscará pautar e delimitar a responsabilidade civil do empregador pela utilização dos agrotóxicos, mediante análise crítica aprofundada dos pontos da legislação que se correlacionam com tais aspectos.

\title{
1. O MEIO AMBIENTE ECOLOGICAMENTE EQUILIBRADO COMO DIREITO HUMANO FUNDAMENTAL
}

O artigo 225 do texto constitucional prescreve que todos têm direito ao meio ambiente ecologicamente equilibrado, bem de uso comum do povo e essencial à sadia qualidade de vida, impondo-se ao poder público e à coletividade o dever de defendê-lo e preservá-lo para presentes e futuras gerações.

$\mathrm{O}$ artigo 225 do texto constitucional decorre das demais normas fundamentais que asseguram ao ser humano uma existência digna, decorre do princípio vetor da dignidade humana. O direito ao meio ambiente ecologicamente equilibrado, nele incluído o meio ambiente 
do trabalho, tem como escopo a manutenção da qualidade de vida, colocada a salvo a fauna, a flora e todos os recursos naturais necessários para a promoção do bem-estar humano (saúde física e mental), o que implica evitar a degradação do meio em que vivemos e eliminar quaisquer riscos que ameacem a existência da espécie humana. Neste sentido, o ideal de desenvolvimento sustentável é um imperativo lógico oriundo da necessidade humana de autopreservação.

Não é por outra razão, que o legislador constituinte estabelece no artigo 170 que a ordem econômica, fundada na livre iniciativa, tem por fim assegurar a todos existência digna, conforme os ditames da justiça social, observados, entre outros, os princípios da função social da propriedade, da defesa do consumidor e da defesa do meio ambiente, inclusive mediante tratamento diferenciado conforme o impacto ambiental dos produtos e serviços e seus processos de elaboração e prestação (incisos III, V e VI).

Sob o aspecto normativo-jurídico, a Constituição da República Federativa do Brasil, consagrou o regime capitalista de produção como apto a assegurar a prosperidade nacional. A noção de desenvolvimento sustentável se submete aos fundamentos republicanos da dignidade humana e dos valores sociais do trabalho e da livre iniciativa.

A construção de uma sociedade livre, justa e solidária, garantido o desenvolvimento nacional, com o objetivo de erradicação da pobreza, só se mostra possível se houver a observância dos ditames da justiça social, que inequivocamente passa pela garantia de proteção dos direitos humanos fundamentais de primeira, segunda e terceira dimensões.

Carlos Henrique Bezerra Leite (2010, p. 34-35) busca esclarecer o conceito de direitos humanos e direitos fundamentais, terminologias que ora se confundem, ora se diferenciam:

Os direitos humanos, por serem universais, estão reconhecidos tanto na Declaração Universal de 1948 quanto nos costumes, princípios jurídicos e tratados internacionais. Já os direitos fundamentais estão positivados nos ordenamentos internos de cada Estado, especialmente nas suas Constituições. Vale dizer, nem todo direito fundamental pode ser considerado um direito humano, assim como nem todo direito humano pode ser considerado um direito fundamental. Exemplifique-se com o direito à vida que, nos termos do art. $5^{\circ}$, caput, da Constituição brasileira de 1988, é um direito fundamental no Brasil, mas é sabido que em alguns ordenamentos jurídicos existe a pena de morte, o que demonstra que em alguns países o direito à vida não é fundamental, embora seja reconhecido como um direito humano no plano internacional.

Não obstante, parece-me que a Constituição Federal de 1988, no seu título II, positivou praticamente todos os direitos humanos, especialmente pela redação dos parágrafos $2^{\circ}$ e $3^{\circ}$ do artigo $5^{\circ}$, razão pela qual não há motivo 
para a distinção, pelo menos do ponto de vista do direito interno, entre direitos fundamentais e direitos humanos. Aliás, o próprio artigo $4^{\circ}$, inciso II, da Constituição Federal, estabelece que, nas relações internacionais, o Brasil adotará o princípio da "prevalência dos direitos humanos". Assim, não seria razoável admitir que na ordem internacional o Brasil adote o princípio da prevalência dos direitos humanos e no plano interno deixe de observá-lo. Talvez sejam essas considerações que levam alguns autores a empregar o termo "direitos humanos fundamentais", como Sérgio Rezende de Barros e Alexandre de Moraes.

\section{Guilherme Guimarães Feliciano (2012, p. 5-6) tece argutas e esclarecedoras} considerações ao associar os direitos do homem ao progresso histórico da civilização. Neste caminho evolutivo, a positivação de direitos fundamentais reflete as escolhas valorativas da sociedade em determinado momento, processo que implica antinomias normativas (colisão de direitos) próprias do Estado Democrático de Direito.

Neste sentido, o embate entre o direito ao meio ambiente ecologicamente equilibrado e a necessidade de desenvolvimento, que no Brasil deve ocorrer no âmbito de um sistema econômico capitalista. Obviamente, este sistema não pode contemplar a exploração dos recursos naturais e humanos (refiro-me aqui ao trabalho humano) que leve ao adoecimento e à morte das pessoas.

Aurélio Virgílio Veiga Rios (2002, p. 1678-1679) faz considerações bastante pertinentes:

Neste sentido, há um direito ao desenvolvimento sustentável, como parte integrante dos direitos humanos, que incorpora dois princípios: o primeiro proclama o direito de cada Estado buscar os meios próprios de desenvolvimento social e econômico e, o segundo princípio, pontifica que a legítima busca dos meios de produção de riqueza não pode inviabilizar a presença humana no planeta, através da deterioração da qualidade de vida no planeta.

Para usarmos a feliz síntese da Comissão Brundtland sobre Meio Ambiente e Desenvolvimento no documento chamado Nosso Futuro Comum, desenvolvimento sustentável significa que cada país deve buscar os meios necessários para o seu desenvolvimento, desde que não comprometam a possibilidade das gerações futuras encontrarem seus próprios meios de sobrevivência e de desenvolvimento.

(...).

Neste sentido, a questão que se põe é como definir, precisamente, o que seja desenvolvimento sustentável. Cada Estado ou corporação privada sempre alegará que a sua intervenção no meio ambiente é sustentável, mesmo se efeitos adversos graves advirem dessas atividades econômicas ou mesmo de políticas públicas. Atualmente, a defesa da sustentabilidade não dá parâmetros objetivos para avaliar a distância entre a teoria ou o discurso ecologicamente correto e a prática da destruição de ecossistemas e habitats por conta dessas mesmas políticas ou atividades.

(...). 
Não obstante essas dificuldades de harmonização e interpretação da ideia do desenvolvimento sustentável, a Declaração do Rio, nascida da Conferência Mundial sobre Meio Ambiente e Desenvolvimento, estabeleceu princípios que incorporam os pressupostos do direito intergeracional ao desenvolvimento sustentável, como, por exemplo, a qualidade de vida e de trabalho de modo a assegurar a todo homem saúde e uma vida produtiva em harmonia com a natureza (princípio $\mathrm{n}^{\circ} 01$ ); a necessidade de garantir o desenvolvimento harmônico para as presentes e futuras gerações (princípio $\mathrm{n}^{\circ}$ 03) e que a proteção ambiental seja parte integrante do desenvolvimento econômico (princípio $\mathrm{n}^{\circ}$ 04) e que, para alcançar as metas do desenvolvimento sustentável e garantir a qualidade de vida para todos os povos, os Estados devem reduzir ou eliminar os processos de produção e consumo insustentáveis (princípio $\mathrm{n}^{\circ} 08$ ).

Neste contexto, as normas jurídicas devem ser efetivas, assegurados instrumentos jurídicos capazes de entregar tutela jurisdicional adequada e pronta para a eliminação dos riscos. $\mathrm{O}$ atual momento histórico da humanidade exige normas jurídicas caracterizadas pela mobilidade e plasticidade, entendidas estas qualidades como aquelas aptas ao acompanhamento das constantes novidades impostas pela globalização econômica, no mais das vezes, ameaçadoras do meio ambiente ecologicamente equilibrado e, portanto, impeditivas da sadia qualidade de vida.

Quanto às dimensões dos direitos humanos fundamentais, retratam o progresso histórico da humanidade e a superação das concepções político-jurídicas no decorrer do tempo. Os direitos de primeira dimensão, direitos negativos do indivíduo em face do Estado, configuram liberdades públicas, trata-se da superação do Estado absolutista. Os direitos de segunda dimensão referem-se aos direitos sociais (destaque para os direitos trabalhistas), à exigência de prestações positivas do Estado, trata-se da superação do Estado liberal focado nas concepções individualistas (pós $1^{\text {a }}$ Guerra Mundial).

O meio ambiente se encaixa nos direitos de terceira dimensão, cujo fundamento maior é o princípio da solidariedade (forte no direito ambiental e previdenciário), conforme Feliciano (2012, p. 8):

Os direitos humanos de terceira geração definem-se como "direitos de solidariedade: direito à paz, ao desenvolvimento, ao respeito ao patrimônio comum da humanidade, ao meio ambiente". Tais direitos estão ligados ao valor da fraternidade (= solidariedade), completando o tríduo axiológico da Revolução Francesa de 1789.

Essa classe de direitos envolve um processo de coletivização dos interesses e destinatários (forjando-se o conceito de interesses difusos) e de especificação dos sujeitos titulares (consideração do indivíduo humano "uti singulus": a criança, a mulher, o adolescente, o consumidor, o contribuinte, o deficiente, o idoso, etc.). Eis aqui o ponto de inflexão dos direitos de terceira geração, uma vez que, nas liberdades singulares do século XVIII, pensava-se 
o homem "in abstracto", sob o pálio da igualdade formal. Na terceira geração, porém, os direitos e os homens diferenciam-se em função do gênero (homem vs. mulher), das várias fases da vida (direitos da infância e da juventude, direitos do idoso) e dos vários estados excepcionais (deficientes físicos e mentais - ou portadores de necessidades especiais, na expressão mais atual), entre outros. No âmbito internacional, vão às centenas os textos jurídicos tributários da perspectiva do homem "ut singulus", como a Declaração dos Direitos da Criança (1959) e a Declaração dos Direitos do Deficiente Mental (1971). No âmbito interno, são

célebres exemplos o Estatuto da Criança e do Adolescente (Lei n. 8.069/90), o Código de Defesa do Consumidor (Lei n. 8.078/90), o recente Estatuto do Idoso (Lei n. 10.741/2003) e, "de jure constituendo", o Código de Defesa do Contribuinte (PLC n. 646/99, em tramitação no Senado Federal). Refiram-se ainda, como direitos de terceira geração, o direito ao meio ambiente ecologicamente equilibrado (artigo 225, caput, da CRFB) e os chamados direitos de paz (em geral).

Discorreu-se sobre o meio ambiente ecologicamente equilibrado e a sua posição jurídica de proeminência no ordenamento jurídico nacional, contudo, importante definir sob o aspecto normativo-jurídico qual o alcance do termo.

A definição legal se encontra no artigo $3^{\circ}$, inciso I, da Lei $n^{\circ}$ 6.938/81: "entende-se por meio ambiente o conjunto de condições, leis, influências e interações de ordem física, química e biológica, que permite, abriga e rege a vida em todas as suas formas”.

O conceito legal é amplo, o que se mostra bastante proveitoso, uma vez que evita interpretações restritivas daqueles que buscam o desenvolvimento a qualquer preço, sempre resistentes a mudanças nos processos produtivos causadores de degradação ambiental e de poluição (vide conceituação destes termos no artigo $3^{\circ}$, incisos II e III, da Lei $n^{\circ}$ 6.938/81).

A característica multidisciplinar e transversal própria ao conceito de meio ambiente acentua a simbiose existente com outros direitos humanos fundamentais positivados, tais como o direito à saúde, cuja acepção jurídica é igualmente ampla.

Helita Barreira Custódio (2001, p. 12-13), em artigo sobre o direito à saúde e problemática dos agrotóxicos, bem apreende a noção do termo saúde, transpondo-o para o campo dogmático:

Em resumo, a saúde constitui um bem público constitucionalmente assegurado, garantido e protegido ao pleno bem-estar de todos. Em razão das desafiantes e abrangentes questões contemporâneas relacionadas com a saúde, trata-se de noção vinculada a um complexo de harmônicas ações prioritárias, permanentes e preventivas, ajustáveis ao equilibrado estado de salubridade ambiental, em progressivas condições favoráveis à promoção, à proteção, à recuperação e à melhoria da saúde pública e à conservação da vida. No Direito Internacional, perante a Organização Mundial da Saúde, observase a ampliação do conceito de saúde, diante do aumento e agravamento dos 
prejudiciais efeitos contrários decorrentes de atividades, condutas ou procedimentos perigosos que possam ocasionar dano não só ao estado físico ou psíquico da pessoa humana, mas também a qualquer realidade da vida social, como a segurança, a tranquilidade, a liberdade, a igualdade, a propriedade, o trabalho, a educação, enfim, toda causa ou efeito prejudicial ao bem-estar do cidadão em sociedade, individual, coletiva ou publicamente considerado, diante dos progressivos fenômenos danosos, notadamente da poluição ambiental. Assim, superado o conceito tradicional e condicionado à falta de enfermidades, em razão da contínua gravidade e ampliação das "moléstias de civilização", considera-se saúde, para os fins de proteção contra as condutas lesivas, dentre outras, ao meio ambiente, "o estado de completo bem-estar físico, mental e social, e não apenas a ausência de moléstias e enfermidades".

Entendido o direito ao meio ambiente ecologicamente equilibrado como direito humano fundamental, cabe estudar o direito ao meio ambiente do trabalho hígido como direito humano fundamental. Partindo-se desta premissa, toda atividade empresarial que adote método de trabalho caracterizado pelo uso de equipamentos e produtos perigosos, sem que haja a eliminação dos riscos ao trabalhador, ou, ao menos, a neutralização destes, não pode ser tolerada.

\section{OS DIREITOS CONSTITUCIONAIS TRABALHISTAS E O MEIO AMBIENTE DO TRABALHO HÍGIDO COMO DIREITO HUMANO FUNDAMENTAL}

A Revolução Industrial acentuou a exploração do trabalho humano e despertou a consciência da classe trabalhadora para a necessidade de regras protetivas contra o modelo capitalista predatório (SOUTO MAIOR, 2011, p. 165-166).

A sociedade do final do século XIX descobre que os direitos conquistados com a Revolução Francesa não são suficientes para impedir os desmandos da classe dominante, a burguesia, preocupada com a manutenção do poder político e econômico, tanto que foram estabelecidos direitos civis e políticos voltados precipuamente para o combate ao Estado absolutista. Souto Maior expõe os silogismos da filosofia liberal dominante (2011, p. 164165):

Ademais, as leis em questão se inseriam no contexto da reinante filosofia liberal e da ordem jurídica que dela advinha, o direito liberal, cujos postulados, segundo feliz síntese de François Ewald, podem ser assim expressos: a) a preocupação com o próximo decorre de um dever moral: tornar esse dever em uma obrigação jurídica elimina a moral que deve existir como essência da coesão social; b) todo direito obrigacional emana de um contrato: a sociedade 
não deve obrigação a seus membros; só se reclama um direito em face de outro com quem se vincule pela via de um contrato; c) a desigualdade social é consequência da economia (e a igualdade, também): quando o direito procura diminuir a desigualdade, acaba acirrando a guerra entre ricos e pobres (ricos obrigados à benevolência, buscam eliminar o peso do custo de tal obrigação; pobres, com direitos, tornam-se violentos); d) a fraternidade é um conceito vago que não pode ser definido em termos obrigacionais; e) o direito só tem sentido para constituir a liberdade nas relações intersubjetivas, pressupondo a igualdade (a ordem jurídica tem a função de impedir os obstáculos à liberdade); f) o direito não pode obrigar alguém a fazer o bem a outra pessoa; g) 'em uma sociedade constituída segundo o princípio da liberdade, a pobreza não fornece direitos, ela confere deveres.

O direito do trabalho surge como resposta aos desmandos dos proprietários dos meios de produção, não sendo mais possível a continuidade da passividade estatal. $\mathrm{O}$ intervencionismo estatal traz consigo a ideia do Estado provedor, do Estado de Bem-Estar Social, que opera para estabelecer algum equilíbrio nas relações sociais pautadas pela primazia de uma parte em detrimento da outra. Após as duas Grandes Guerras Mundiais, esta necessidade de frear os impulsos de uma sociedade corrompida pela ânsia de poder e de riqueza a qualquer custo se consolida.

A constitucionalização das normas jurídicas trabalhistas surge naquele momento histórico, com destaque para a Constituição Mexicana de 1917 e a experiência alemã da República de Weimar logo após a $1^{\text {a }}$ Guerra Mundial ${ }^{1}$. Com a criação da Organização Internacional do Trabalho em 1919, os países europeus passam a encampar em seus ordenamentos jurídicos a proteção trabalhista.

No Brasil, o processo histórico impôs ritmo diverso no que concerne às conquistas trabalhistas, questão que ganha força a partir do Governo de Getúlio Vargas.

Não é objeto deste estudo a análise do contexto histórico evolutivo do direito do trabalho no Brasil, de modo que o corte metodológico se faz necessário para concentrar as atenções na Constituição da República de 1988, com a busca do fundamento dogmático que coloca o meio ambiente do trabalho como direito humano fundamental.

\footnotetext{
${ }^{1} \mathrm{O}$ contexto histórico que culminou nas duas Constituições é rico e cercado de peculiaridades. As motivações de cada país foram distintas, em especial no caso mexicano, caracterizado por uma sociedade agrária e de economia capitalista incipiente. $\mathrm{O}$ fato é que houve a constitucionalização dos direitos trabalhistas.
} 
O artigo $7^{\circ}$, inciso XXII, da Constituição da República, estabelece que são direitos dos trabalhadores urbanos e rurais, além de outros que visem à melhoria da sua condição social, a redução dos riscos inerentes ao trabalho, por meio de normas de saúde, higiene e segurança.

No título VIII da Constituição da República, que trata da ordem social, o artigo 193 realça a importância do trabalho: "a ordem social tem como base o primado do trabalho, e como objetivo o bem-estar e a justiça sociais".

Estes dispositivos são aumentados em grau de importância quando assimilados na perspectiva dos fundamentos republicanos da dignidade humana e do valor social do trabalho, como já exposto nos tópicos precedentes.

Obviamente, o trabalho digno depende da garantia de segurança no ambiente de trabalho. O empregador tem o dever de controlar os riscos advindos da atividade produtiva.

A cláusula aberta constante da parte final do caput do artigo $7^{\circ}$ reforça o princípio da proteção inerente ao direito do trabalho.

Sebastião Geraldo de Oliveira (2011, p. 46) expõe com bastante propriedade o significado deste princípio, correlacionando-o às normas de saúde e segurança trabalhistas:

Como adverte Américo Plá Rodriguez, "o legislador não pode mais manter a ficção de igualdade existente entre as partes do contrato de trabalho e inclinouse para uma compensação dessa desigualdade econômica desfavorável ao trabalhador com uma proteção jurídica a ele favorável. O Direito do Trabalho responde fundamentalmente ao propósito de nivelar desigualdades".

$\mathrm{O}$ aspecto protetor permeia todo o edifício da legislação laboral, culminando nas regras de proteção à segurança, higiene e saúde do trabalhador. A CLT destina o Título II às normas gerais de tutela do trabalho e o Título III às normas especiais de tutela, deixando evidente esse princípio estrutural que norteia todos os desdobramentos das regras jurídico-trabalhistas. Afirma Arnaldo Süssekind que "a necessidade de proteção social aos trabalhadores constitui a raiz sociológica do Direito do Trabalho e é imanente a todo o seu sistema jurídico.

O princípio da proteção manifesta-se em três formas distintas: a) a regra "in dubio pro operario", pela qual o aplicador do direito, no caso de haver várias interpretações possíveis, deve optar por aquela que mais favoreça ao empregado; b) a regra da norma mais favorável, que autoriza a aplicar aquela disposição que mais favorecer o empregado, independentemente dos critérios clássicos da hierarquia das fontes; c) a regra da condição mais benéfica, segundo a qual uma nova condição nunca deve servir para diminuir as condições mais favoráveis já alcançadas pelo trabalhador.

O meio ambiente do trabalho é protegido constitucionalmente, conforme estabelece o inciso VIII do artigo 200 da Constituição da República.

Ao discorrer sobre os movimentos do início do século XXI que cuidam do meio ambiente do trabalho, constatados os progressos nos aspectos da conscientização dos problemas 
e avanços legislativos no mundo das normas jurídicas de prevenção e proteção, Sebastião Geraldo de Oliveira (2011, p. 77) menciona os esforços da OIT e OMS para reversão da crise de efetividade:

Nessa mesma toada, a Declaração de Seul, publicada por ocasião do XVIII Congresso mundial sobre segurança e saúde no trabalho, realizado em 2008, menciona que "o direito a um ambiente de trabalho seguro e saudável deve ser reconhecido como um direito humano fundamental e que a globalização deve ser acompanhada de medidas preventivas que garantam a segurança e saúde de todos no trabalho". Enfatiza também que "a promoção de elevados níveis de segurança e saúde no trabalho é uma responsabilidade da sociedade no seu conjunto e que todos os membros da sociedade devem contribuir para esse objetivo, garantindo que os planos nacionais concedam prioridade à segurança e saúde no trabalho, bem como ao estabelecimento e fomento de uma cultura nacional de prevenção em matéria de segurança e saúde no trabalho".

Na seção II do capítulo II da Constituição da República, cuida-se da saúde, merecendo destaque o artigo 200 e seus incisos II, VII e VIII.

O trabalhador possui o direito fundamental à saúde e à proteção contra todas as nocividades que possam causar-lhe agravos.

Estes comandos normativos impõem ao poder público e ao particular (eficácia horizontal dos direitos humanos individuais e sociais fundamentais) a necessidade de agirem preventivamente para o impedimento da contaminação do meio ambiente do trabalho, com o desenvolvimento de técnicas e métodos que eliminem as fontes tóxicas. Na impossibilidade manifesta de eliminação, o potencial poluidor deve ser neutralizado. Caso haja efeito nocivo à saúde do trabalhador, o empregador responderá objetivamente pelos danos causados, uma vez que os agrotóxicos são substâncias notoriamente poluentes, conforme aponta Paulo Afonso Brum (2011, p. 22):

É a circulação social dos produtos tóxicos que impõe a necessidade de que os mesmos passem, de uma forma ou de outra, ao campo da ordem jurídica, impondo-se-lhes um quadro normativo e dogmático. Ou seja, dogmatiza-se aquilo que, em essência, é antagônico ao dogma. Dá-se certeza à incerteza. (...).

Com efeito, impende verificar como as externalidades (positivas e negativas) serão socialmente repartidas. É a partir disto que a ordem jurídica deve se pronunciar no sentido de estabelecer o equilíbrio que foi alterado pela circulação social do produto tóxico. 
Esse o dilema que enfrentamos no tratamento jurídico das substâncias tóxicas. Elas são lesivas por natureza. Não obstante, há necessidade de sua utilização, o que impõe, em consequência, o estabelecimento de regras rígidas de controle sobre o uso. Sabemos de antemão, no entanto, que o disciplinamento jurídico da matéria nem sempre consegue evitar a ocorrência do dano. Há situações em que as regras postas conseguem, quando muito, se obedecidas, atenuar os efeitos da agressão.

É sob essa perspectiva que deve ser analisada a responsabilidade do fabricante quando a lesão advenha da nocividade em si do produto agrotóxico. Aqui já não se pode falar mais em exclusão de responsabilidade. Quem assume o risco de produzir e introduzir no comércio substância agressiva ao meio ambiente ou à saúde humana deve arcar com a responsabilidade de reparar o dano. E nem importa saber se o responsável pela introdução do produto estava ou não autorizado a fazê-lo pelos órgãos estatais encarregados do controle e da fiscalização. No campo da responsabilidade civil objetiva, reafirma-se, mostra-se indiferente a licitude da conduta. Mesmo que licenciada, a atividade que cause lesão ao meio ambiente, afetando o seu equilíbrio, gera responsabilidade civil ao seu agente.

Até aqui, verifica-se que as normas jurídicas constitucionais (princípios e regras) afetas ao meio ambiente, nele incluído o do trabalho, correlacionam-se com outros princípios constitucionais igualmente importantes, formando um tecido dogmático capaz de produzir efeitos imediatos, dotando o intérprete e o Estado-Juiz de mecanismos garantidores da solução adequada aos novos, candentes e complexos problemas da sociedade moderna.

Do direito do trabalho, verdadeiro direito social das gentes, nada menos se espera que a aptidão para debelar a crise de efetividade tão alardeada pelos juristas no campo da saúde do trabalhador. Fundamentos ontológicos e deontológicos próprios deste ramo do direito, criado e vocacionado para a defesa do trabalhador contra a opressão do regime capitalista de produção (apesar de muitos inimigos da lógica jurídica vaticinarem o contrário), não faltam, como exposto.

O renomado processualista Barbosa Moreira, citado por Sebastião Geraldo Oliveira (2011, p. 50-51), alertou logo após a promulgação da Constituição da República de 1988:

Se nos acostumamos a dar aos nossos problemas, por tempo considerável, as mesmas soluções, há forte probabilidade de que pelo menos alguns de nós encarem com pouco entusiasmo o desafio de procurar novas soluções ou - 
pior ainda - de enfrentar novos problemas (...) Manifesta-se em alguns setores da doutrina e da jurisprudência, certa propensão a interpretar o texto novo de maneira que ele fique tão parecido quanto possível com o antigo.

Uma postura tímida, por parte da jurisprudência, já importará renúncia a extrair da Constituição as virtualidades que nela palpitam. Uma atitude de hostilidade, então, poderá inutilizá-la por completo. Não é de crer que os juízes brasileiros pretendam atrasar desse modo o relógio da História. (...) Urge que o texto promulgado se transfigure em vivência. Nossa ardente esperança é a de que o Poder Judiciário não participe desse episódio como espectador frio, nem - pior ainda - como sabotador voluntário ou involuntário, mas como sincero e empenhado colaborador.

As normas jurídicas internacionais afetas à temática do meio ambiente do trabalho não deixam dúvida acerca do seu caráter de direito humano fundamental.

\section{A TORMENTOSA QUESTÃO ATINENTE AO CONTROLE DOS RISCOS DOS AGROTÓXICOS}

Os estudos científicos sobre os agrotóxicos apontam conclusivamente para o perigo destas substâncias contaminantes.

Paulo Afonso Brum Vaz destaca algumas constatações, corroborando outros estudos científicos (2001, p. 16):

a) Em sua maioria, os agrotóxicos são extremamente voláteis, portanto, têm a propriedade de serem carreados pelas correntes aéreas locais e distâncias indesejadas, contaminando extensões incalculáveis do solo, das águas e do ar. As aplicações aéreas, geralmente feitas sem maiores cuidados, representam foco de intensa degradação ambiental, afetando todas as espécies de vida. É hábito lavar os tanques dos aviões, embalagens usadas e equipamentos de aplicação em cursos d'água (rios, lagos, etc.). De 1825 amostras colhidas nos rios paranaenses, por exemplo, 84\% apresentavam resíduos de pelo menos 17 diferentes agrotóxicos;

b) Quase todos os agrotóxicos permanecem no solo por muitos anos, transferindo-se para a cultura seguinte e contaminando também as pastagens que os agropecuaristas costumam plantar entre uma cultura e outra. Estas pastagens são ingeridas pelo gado, contaminando sua carne, que ainda é o alimento preferido da população brasileira;

c) Com o emprego de agrotóxicos, ao longo do tempo, um número razoável de pragas, que atacam a lavoura, quase igual ao que é destruído, adquire resistência, tornando-se imune e obrigando, como que num círculo vicioso, à criação de novas e mais potentes fórmulas. Do universo de insetos destruídos, muitos são benignos, como a abelha e os demais insetos polinizadores, tão necessários ao equilíbrio ecológico;

d) Um dos problemas diretos mais graves é exatamente a excessiva concentração de resíduos de agrotóxicos nos alimentos de origem vegetal e animal, principalmente em razão da inobservância do número correto de aplicações, das dosagens recomendadas ou dos intervalos de tempo necessários entre a aplicação e a colheita. Pesquisas têm revelado altas 
concentrações de resíduos tóxicos em frutas, em verduras e em carne bovina. e) Por fim, vale destacar alguns efeitos decorrentes da contaminação por agrotóxicos em seres humanos. Têm-se registros de lesões hepáticas e renais, esterilidade masculina, hiperglicemia, hipersensibilidade, carcinogênese, fibrose pulmonar, redução da imunidade e até suicídios, como têm ocorrido na região fumageira de Venâncio Aires e Santa Cruz, no Rio Grande do Sul, onde o MPF investiga o alto número de suicídios. Acredita-se que se deva ao contato prolongado com algum tipo de agrotóxico empregado na lavoura de fumo.

Se no que concerne à ingestão de alimentos tratados com agrotóxicos, conceitos agronômicos como Limite Máximo de Resíduo² e Ingestão Diária Aceitável ${ }^{3}$ são instrumentos importantes para a avaliação dos riscos, buscando trazer relativa tranquilidade aos consumidores, os mesmos não se aplicam aos trabalhadores que manipulam as substâncias contaminantes $^{4}$ (ESPÍNDOLA, 2011, p. 35) e se colocam em contato pronto e direto com o veneno (LOPES, 2010, p. 26-27) ${ }^{5}$. A Lei $\mathrm{n}^{\circ} 7.802 / 89$ discorre sobre a pesquisa, a experimentação, a produção, a embalagem e rotulagem, o transporte, o armazenamento, a comercialização, a propaganda comercial, a utilização, a importação, a exportação, o destino final dos resíduos e embalagens, o registro, a classificação, o controle, a inspeção e a fiscalização de agrotóxicos, seus componentes e afins. O termo agrotóxico (ESPÍNDOLA, 2011, p. 32) ${ }^{6}$ é o atualmente utilizado pela legislação brasileira, conforme definição do artigo $2^{\circ}$ (OLIVEIRA, 2005, p. 64)7.

2 Define-se Limite Máximo de Resíduo - LMR como a quantidade máxima de resíduo de agrotóxico oficialmente aceita no alimento, em decorrência da aplicação adequada numa forma específica desde a sua produção até o consumo. É expressa em partes (peso) de agrotóxico ou seus resíduos por milhão de partes de alimento - em peso

- ppm ou $\mathrm{mg} / \mathrm{kg}$ de alimento. Sinonímia: tolerância.

3 IDA - Ingestão Diária Aceitável ou Dose Diária Aceitável de um produto químico é a estimativa da quantidade de uma substância em um alimento e/ou bebida-água, expressa sobre uma base de peso corpóreo, que se ingerida diariamente durante toda a vida, parece não oferecer risco apreciável à saúde do consumidor, à luz dos conhecimentos atuais. É usualmente expressa em miligramas e/ou micrograma da substância por quilograma de peso corpóreo (padrão humano adulto).

${ }^{4}$ Afirma a pesquisadora em sua tese de doutorado que há estudos que apontam que a via ocupacional, caracterizada pela contaminação dos trabalhadores quando da manipulação dos produtos, é responsável por $80 \%$

dos casos de intoxicação, não obstante atinja reduzida parcela da população.

5 Estudos relacionados aos impactos do uso dos agrotóxicos revelam que os trabalhadores rurais podem sofrer intoxicações agudas, mesmo quando utilizam o Equipamento de Proteção Individual - EPI, indicando que sua segurança é relativa. Além de esses equipamentos serem desconfortáveis e difíceis de serem usados em climas quentes, o sistema de troca dos filtros das máscaras pelas indústrias é outro agente complicador que leva ao incremento dos casos de envenenamentos. Em algumas aplicações, notadamente através de pulverizadores costais, ocorre absorção desses produtos pela pele, sobretudo quando as roupas do trabalhador ficam encharcadas. Nesses casos, ampliam-se os riscos de contaminação, principalmente quando tais vestimentas são lavadas junto às da família, que, por sua vez, se contaminam. Outra séria implicação que eleva os índices das intoxicações diz respeito às pulverizações aéreas, proibidas na União Europeia, mas ainda permitidas no Brasil, com a única exigência de que seja estabelecida uma distância de 500 metros das comunidades e 250 metros dos mananciais de água. Acrescentam-se, ainda, a exposição combinada ou sequencial às várias substâncias químicas, com diferentes formulações, que podem resultar em níveis severos de envenenamento e poluição ambiental.

${ }^{6}$ Os agrotóxicos se classificam em: 1) Inseticidas: ação de combate a insetos, larvas e formigas; 2) Fungicidas: combate aos fungos; 3) Herbicidas: utilizados no combate a ervas daninhas esse grupo tem tido uma crescente utilização pela agricultura.

${ }^{7}$ A partir da Lei $n^{\circ} 7.802 / 89$, o termo "defensivo agrícola", que distorcia o conceito e fugia da alinhada terminologia internacional, que é "pesticida", foi substituído pelo termo "agrotóxicos", que destaca a noção de

produto perigoso, deixando claro para o agricultor e para a população que o produto é tóxico".

Quanto aos aspectos jurídicos mais importantes da legislação sobre agrotóxicos, a Lei ${ }^{\circ}$ 7.802/89 vai ao encontro dos princípios da precaução, da prevenção e do poluidor-pagador. 
A lei estabelece preceitos importantes para a prevenção dos agravos à saúde daqueles que manipulam os agrotóxicos, nas várias etapas da cadeia produtiva.

Os artigos $3^{\circ}$ e $4^{\circ}$ tratam da necessidade de registro dos agrotóxicos perante os órgãos federais. Cabe destacar os preceitos dos parágrafos $4^{\circ}, 5^{\circ}$ e $6^{\circ}$ do $\operatorname{artigo} 3^{\circ}$, que merecem reprodução:

$\S 4^{\circ}$. Quando organizações internacionais responsáveis pela saúde, alimentação ou meio ambiente, das quais o Brasil seja membro integrante ou signatário de acordos e convênios, alertarem para riscos ou desaconselharem o uso de agrotóxicos, seus componentes e afins, caberá à autoridade competente tomar imediatas providências, sob pena de responsabilidade.

$\S 5^{\circ}$. O registro para novo produto agrotóxico, seus componentes e afins, será concedido se a sua ação tóxica sobre o ser humano e o meio ambiente for comprovadamente igual ou menor do que a daqueles já registrados, para o mesmo fim, segundo os parâmetros fixados na regulamentação desta Lei. $\S 6^{\circ}$. Fica proibido o registro de agrotóxicos, seus componentes e afins:

a) para os quais o Brasil não disponha de métodos para desativação de seus componentes, de modo a impedir que os seus resíduos remanescentes provoquem riscos ao meio ambiente e à saúde pública; b) para os quais não haja antídoto ou tratamento eficaz no Brasil; c) que revelem características teratogênicas, carcinogênicas ou mutagênicas, de acordo com os resultados atualizados de experiências da comunidade científica; d) que provoquem distúrbios hormonais, danos ao aparelho reprodutor, de acordo com procedimentos e experiências atualizadas na comunidade científica; e) que se revelem mais perigosos para o homem do que os testes de laboratório, com animais, tenham podido demonstrar, segundo critérios técnicos e científicos atualizados; f) cujas características causem danos ao meio ambiente.

$\mathrm{O}$ artigo $5^{\circ}$ é deveras importante, porque trata da legitimidade para requerer o cancelamento ou a impugnação, em nome próprio, do registro de agrotóxicos e afins, arguindo prejuízos ao meio ambiente, à saúde humana e dos animais. O inciso III diz da legitimidade das entidades que atuam na defesa dos interesses difusos relacionados à proteção do consumidor, do meio ambiente e dos recursos naturais.

A Lei $\mathrm{n}^{\circ} 7.802 / 89$ é regulamentada pelo Decreto 4.074/2002, que alterou algumas definições (OLIVEIRA, 2005, p. 79).

Verifica-se o rigor normativo quanto ao registro dos agrotóxicos, sendo que o ato administrativo para a concessão é complexo. Ao Ministério da Agricultura, da Pecuária e do Abastecimento (MAPA) cabe a concessão do registro de produtos técnicos usados em áreas agrícolas. Ao Instituto Brasileiro do Meio Ambiente e dos Recursos Naturais Renováveis (IBAMA) cabe a concessão do registro de substâncias químicas relacionadas a áreas não agrícolas. Ao Ministério da Saúde, por intermédio da ANVISA, cabe avaliar e classificar toxicologicamente os agrotóxicos, seus componentes, e afins. As atribuições e competências 
de cada um estão estabelecidas nos artigos $2^{\circ}, 3^{\circ}, 4^{\circ}, 5^{\circ}, 6^{\circ}$ e $7^{\circ}$ do Decreto $n^{\circ} 4.074 / 2002$.

Apesar do rigor normativo, as dificuldades típicas de um país continental, em que a agricultura é fundamental para a economia do país e sua modernização implica o avanço das monoculturas e a utilização cada vez maior de agrotóxicos, a intrincada teia legislativa que cuida da questão do registro destas substâncias não funciona a contento, não obstante o avanço ocorrido após a publicação da Lei n ${ }^{\circ} 7.802 / 89$.

Uma das principais críticas é que o foco da legislação está na proibição de introdução de substâncias tóxicas no mercado mediante um mecanismo de comando e controle, sem que haja um sistema integrado entre os diversos órgãos responsáveis pelo registro capaz de avaliar os riscos existentes (OLIVEIRA, 2005, p. 84). Já quanto ao controle, a ineficácia da fiscalização compromete este propósito (LONDRES, 2011, p. 142-143) ${ }^{8}$ e compromete a efetividade das normas jurídicas (LOPES, 2010, p. 35-36).

A questão da avaliação e do gerenciamento de riscos (CONTE; SOARES, 2001, p. 15; RIOS, 2002, p. 1687), decisiva para a concessão do registro, é tratada na legislação, em especial no Decreto $\mathrm{n}^{\circ}$ 4.074/2002 (OLIVEIRA, 2005, p. 169) ${ }^{9}$, contudo, falta ao Brasil a capacidade institucional para a identificação de problemas relacionados aos agrotóxicos, seja quando do registro, do transporte, da comercialização e do uso das substâncias tóxicas.

Não obstante toda a sorte de dificuldades, a ANVISA procedeu a reavaliações toxicológicas de substâncias existentes, reavaliações que culminaram em restrições e retirada destes produtos do mercado (LONDRES, 2011, p. 148).

$\mathrm{O}$ artigo $5^{\circ}$ da Lei $\mathrm{n}^{\circ} 7.802 / 89$ dá legitimidade aos diversos ramos do Ministério Público para pleitearem o cancelamento e a impugnação do registro de agrotóxicos, conforme expressa previsão do inciso III.

Ressalte-se que a legitimidade do Ministério Público é ampla para a atuação preventiva e repressiva em face dos responsáveis pela contaminação e pelos agravos causados

\footnotetext{
8

Entre julho de 2009 e agosto de 2010, a ANVISA realizou fiscalização em dez fábricas de agrotóxicos, a primeira desde 1999 (ano de criação da agência), e em todas foram encontradas irregularidades graves, tais como: adulteração na fórmula (BAYER); adulteração da data de fabricação e da data de validade (SYNGENTA); prazo de validade vencido e ausência de datas de fabricação e de validade (BASF); omissão de informações sobre o processo de produção dos agrotóxicos (MONSANTO); adulteração da data de fabricação e da data de validade, falta de controle de impurezas e embalagens vazando (DOW AGROSCIENCES); comercialização de produtos vencidos, ausência de datas de fabricação e validade, adulterações de fórmulas (NUFARM); produto comercializado com formulação tóxica acima do permitido (MILENA AGROCIENCIAS); irregularidades no rótulo e bula sobre as informações da classificação toxicológica (IHARABRAS); prazo de validade adulterado, componentes da fórmula em desacordo com o que havia sido aprovado pela ANVISA (SIPCAM ISAGRO BRASIL); produtos vencidos e provenientes de fabricantes não autorizados (FMC QUIMICA DO BRASIL). Houve apreensão de milhões de litros de agrotóxicos, bem como a interdição de linhas de produção. 9

A implementação da avaliação de risco é claramente definida no artigo 95 do Decreto 4.074/2002. Entretanto, como a atividade não é executada, este ponto pode ser caracterizado como um 'fato político', ou seja, um fato que causa impacto, mas não garante a concretização da ação.
} 
à saúde da população, em toda a cadeia produtiva e em todas as etapas que permeiam a questão da utilização dos agrotóxicos.

No que concerne aos aspectos trabalhistas, a legitimidade do Ministério Público do Trabalho é igualmente manifesta, porque o trabalhador poderá ter contato com as substâncias tóxicas quando da produção, da comercialização, do transporte, da manipulação e do uso.

A legislação objeto de análise determina a ação imediata das autoridades competentes quando houver informações sobre a ação danosa dos agrotóxicos à saúde da população, impondo a retirada da substância do mercado (parágrafo $5^{\circ}$ do artigo $3^{\circ}$ ). Neste aspecto, reafirmada a força normativa das convenções e tratados internacionais sobre a temática, reconhecendo os esforços mundiais na busca de um desenvolvimento sustentável (parágrafo $4^{\circ}$ do artigo $3^{\circ}$ ).

Estas normas legais permitem a atuação do Ministério Público do Trabalho preventivamente, com o escopo de não permitir a utilização de determinado agrotóxico pelo trabalhador ou de exigir do empregador a substituição por outro de menor toxicidade (GARCIA; ALVES FILHO, 2005, p. 16). Neste sentido, tais medidas são preferíveis a outras que não têm o condão de eliminar ou neutralizar a possibilidade de contaminação.

Tendo em vista a grande quantidade destas substâncias no mercado e as facilidades para a aquisição, não obstante a dificuldade em avaliar os riscos da utilização de determinado agrotóxico, a possibilidade de pleitear o cancelamento ou impugnar o registro deste é um caminho jurídico importante e que pode mostrar-se eficaz e efetivo para a proteção do trabalhador.

Possível e recomendável exigir do empregador ações que diminuam os riscos de toxicidade ao trabalhador rural que manipula ou aplica agrotóxicos. Os princípios da precaução e da prevenção facultam a dedução de uma pretensão no âmbito de uma Ação Civil Pública que exija a substituição por um produto menos tóxico, tão ou mais eficaz quanto aquele de maior grau de toxicidade para o combate de determinada praga agrícola ${ }^{10}$.

A adoção deste princípio vai mais além: permite ao Ministério Público do Trabalho

\footnotetext{
10

Os agrotóxicos são classificados conforme o grau de toxicidade, potencial de periculosidade ambiental. $\mathrm{O}$ artigo $3^{\circ}$ da Portaria Normativa IBAMA n 84, de 15 de outubro de 1996, baseando-se em parâmetros de bioacumulação, persistência, transporte, toxicidade a diversos organismos, potencial mutagênico, teratogênico, carcinogênico, divide-os em: Classe I Produto Altamente Perigoso; Classe II - Produto Muito Perigoso; Classe III - Produto Perigoso; Classe IV - Produto Pouco Perigoso. O parágrafo único estabelece que não será concedido o registro aos agrotóxicos, seus componentes e afins, se: a) não houver disponibilidade no país de métodos para sua desativação e de seus componentes, como preceitua a alínea a, do $\S 6^{\circ}$, do artigo $3^{\circ}$, da Lei 7.802 e inciso I, do artigo 22, do Decreto 98.816; b) apresentar características mutagênicas, teratogênicas ou carcinogênicas referidas na alínea c, do $§ 6^{\circ}$, do artigo $3^{\circ}$, da Lei 7.802 e incisos III, IV e V, do artigo 22, do Decreto 98.816; c) a classificação de PPA e/ou avaliação do risco ambiental indicarem índices não aceitáveis de periculosidade e/ou risco, considerando os usos propostos.
} 
exigir a não utilização de determinado produto quando houver indícios acerca dos males causados à saúde humana, uma vez que os interesses empresariais nunca poderão significar a superação do direito natural à vida e à preservação da dignidade humana.

Ressalte-se que avaliar o grau de toxicidade de determinada substância química não é uma tarefa simples, trata-se de um processo cercado por dúvidas e incertezas, em que fatores externos podem aumentar consideravelmente o risco. Estes fatores, próprios ao meio ambiente de trabalho ou ao indivíduo exposto, interferem significativamente na avaliação dos riscos criados (GARCIA; ALVES FILHO, 2005, p. 16).

\section{A QUESTÃO DA RESPONSABILIDADE CIVIL DO EMPREGADOR PELOS ILÍCITOS E DANOS AO TRABALHADOR QUE MANIPULA AGROTÓXICOS}

O artigo 14 da Lei $\mathrm{n}^{\circ} 7.802 / 89$ imputa as responsabilidades de cada sujeito inserido na cadeia produtiva dos agrotóxicos.

Ao profissional pode ser imputadas responsabilidades administrativa, civil e penal pelos danos causados à saúde das pessoas e ao meio ambiente, quando comprovada receita errada, displicente ou indevida.

Ao usuário ou ao prestador de serviços, quando proceder em desacordo com o receituário ou as recomendações do fabricante e órgãos registrantes e sanitário-ambientais.

Ao comerciante, quando efetuar venda sem o respectivo receituário ou em desacordo com a receita ou recomendações do fabricante e órgãos registrantes e sanitário-ambientais.

Ao registrante que, por dolo ou por culpa, omitir informações ou fornecer informações incorretas.

Ao produtor, quando produzir mercadorias em desacordo com as especificações constantes do registro do produto, do rótulo, da bula, do folheto e da propaganda, ou não der destinação às embalagens vazias em conformidade com a legislação pertinente.

Ao empregador, quando não fornecer e não fizer manutenção dos equipamentos adequados à proteção da saúde dos trabalhadores ou dos equipamentos na produção, distribuição e aplicação dos produtos.

A leitura da regra jurídica merece correta interpretação, haja vista que o compartimento de responsabilidades não implica, absolutamente, a impunidade daquele que agiu e contribuiu para a ocorrência da conduta ilícita, independentemente de sua qualificação, 
usuário, comerciante, registrante, produtor ou empregador. A responsabilidade do empregador não está adstrita às hipóteses descritas na letra " $\mathrm{f}$ ” do artigo 14. Paulo Affonso Leme Machado (2012, p. 757-758) chama a atenção para a questão ${ }^{11}$ :

Teria a lei isentado de responsabilidade o usuário que seguisse a receita e, mesmo assim, danos fossem constatados com referência à saúde e ao meio ambiente? A responsabilidade seria somente do profissional que emitiu a receita? Seria a receita a única norma obrigatória para o usuário, liberando-o completamente de outros cuidados não previstos naquela prescrição? Entendemos que, inobstante deva apurar-se a responsabilidade do emissor da receita, nem por isso fica - de plano - afastada a corresponsabilidade do usuário. Ninguém na coletividade brasileira pode sustentar que não é corresponsável pelo meio ambiente diante da redação do art. 225, caput, da CF, máxime o usuário de agrotóxicos.

Uma interpretação não atenta para as finalidades protetoras dos valores da produção agrícola e florestal, mas também da saúde humana e do meio ambiente, poderia levar o intérprete a considerar o registro e a receita como únicos e supremos árbitros da utilização do agrotóxico no País. Se esquecermos os avanços da introdução da responsabilidade civil objetiva pelos danos causados ao meio ambiente (art. 14, par. $1^{\circ}$, da Lei de Política Nacional do Meio Ambiente - Lei 6.938, de 31/08/1981), teremos alimentos consumidos no País contaminados por agrotóxicos, com as vítimas e a coletividade sujeitas à difícil e ingrata tarefa de ter que provar que o usuário de agrotóxicos descumpriu uma receita. Evidente que este ônus da prova não pode cair sobre as vítimas dos alimentos provindos da cultura do usuário, pois seria quase impossível aos consumidores apontar o cumprimento de situações de fato como a observância dos intervalos de segurança entre a aplicação do agrotóxico e a colheita dos produtos agrícolas.

O empregador ou aquele que se vale do prestador de serviços (trabalhador que manipula os agrotóxicos) responde objetivamente pelos danos causados à saúde deste, independentemente de culpa. Ou seja, comprovada a intoxicação do trabalhador em razão da manipulação de agrotóxicos, o empregador deve ser responsabilizado, isoladamente ou solidariamente com os demais sujeitos que deixaram de observar a legislação regente da temática (VAZ, 2001, p. 23). A letra “f” do artigo 14 da Lei n 7.802/89 imputa ao empregador a responsabilidade em caso de não fornecimento ou ausência de manutenção de EPIs e equipamentos utilizados na aplicação dos agrotóxicos. Verifica-se a miopia do legislador ordinário quando da edição da lei, o que reflete a displicência com aquele que é o mais afetado pela atividade danosa (o trabalhador rural) e a cultura trabalhista de atraso, que foca as medidas de proteção no indivíduo e não na fonte causadora do risco agravado, o próprio ambiente de trabalho.

O autor define usuário como toda pessoa física ou jurídica que utilize agrotóxico ou afins, sendo que utilizar é empregar utilmente, é tirar vantagem, é servir-se. 
Obviamente, a proteção trabalhista vai muito além deste dispositivo, haja vista os preceitos constitucionais e as normas internacionais (Convenções e Recomendações da OIT) ${ }^{12}$ e nacionais

(CLT e Normas Regulamentadoras do Trabalho e Emprego que tratam da saúde, segurança e higiene trabalhistas) ${ }^{13}$ aplicáveis ao meio ambiente do trabalho.

Salvo em caso de comprovação de culpa exclusiva da vítima, que afeta o nexo causal entre a conduta ilícita e o dano causado ao trabalhador, a responsabilidade do empregador será objetiva. Não há limites seguros para exposição aos agrotóxicos ${ }^{14}$, sendo que qualquer função exercida que implique o contato com as substâncias contaminantes é considerada uma atividade de risco. Neste contexto, atrai-se a aplicação do parágrafo único do artigo 927 do Código Civil ${ }^{15}$. Guilherme Guimarães Feliciano (2011, p. 300), ao tratar da responsabilidade civil que decorre do risco da atividade, expõe:

Cediço, portanto, que o constituinte reconheceu a independência conceitual do meio ambiente do trabalho; mas o fez sem perder de vista a concepção integrada do meio ambiente humano como gestalt, recolhendo aquela primeira manifestação gestáltica sob a guarida da disciplina geral do meio ambiente. Remanesce, então, a perplexidade: por que se teria dado um diverso tratamento jurídico, em tema de responsabilidade aquiliana?

(...). Nada obstante, a lição não deixa transparecer, com toda a sua força, a ratio juris da distinção, por detrás do conceito "a se" de poluição laborambiental (e não no caráter "individual" ou "coletivo" da ameaça, como poderia parecer). Com efeito, poluição (art. $3^{\circ}$, III, da Lei ${ }^{\circ}$ 6.938/1981) e riscos ambientais (art. 22, II, da Lei $n^{\circ} 8.212 / 1991$ ) não se confundem. Os riscos são inerentes a toda e qualquer atividade econômica; e, mais além, à maior parte das atividades sociais organizadas da sociedade pós-industrial. Dito de outro modo, as necessidades da civilização - naturais ou induzidas e os avanços da técnica ensejam, hodiernamente, "riscos de procedência humana como fenômeno social estrutural". São, pois, riscos toleráveis até certo limite. Daí justamente se extrai o arco ético permissivo que admite abrigar tanto a norma do art. $7^{\circ}$, XXVII, da CRFB, como os limites de

\footnotetext{
${ }^{12}$ Entre tantas convenções e recomendações da Organização Internacional do Trabalho, podem ser citadas: 155 - política nacional em matéria de saúde e segurança dos trabalhadores e sobre meio ambiente do trabalho; 161 - serviços de saúde no local de trabalho; 170 segurança na utilização de produtos químicos no trabalho, todas ra- tificadas pelo Brasil. Mais especificamente no que tange aos agrotóxicos, há convenções assinadas pelo Brasil bastante específicas, a Convenção sobre o Consentimento Prévio Fundamentado Aplicável a Certos Agrotóxicos e Produtos Químicos Perigosos Objeto de Comércio Internacional - Convenção de Roterdã ou Convenção PIC - e a Convenção de Estocolmo sobre Poluentes Orgânicos Persistentes - Convenção POPs (citadas no documento final da Rio+20, item 216). As Convenções referidas foram aprovadas pelo Brasil em 07 de maio de 2004, medi- ante os Decretos Legislativos 197 e 204, e promulgadas pelos Decretos $5.360 / 2005$ e $5.472 / 2005$.

13 Dest

${ }^{13}$ Destaque para a Norma Regulamentadora n ${ }^{\circ} 31$ do Ministério do Trabalho e Emprego, que trata de normas de saúde e segurança para os trabalhadores da agricultura, sendo que o item 31.8 traz regras referentes aos agrotóxi- cos. Tais normas têm força de lei em virtude da disposição do artigo 200 da Consolidação das Leis do Trabalho - CLT. A NR foi editada em 2005, o que comprova o atraso civilizatório brasileiro e a dívida histórica com os tra-balhadores rurais. No que tange aos agrotóxicos, é o único normativo categórico e sistematizado em torno da necessidade de proteção dos trabalhadores rurais.

${ }^{14}$ A nocividade dos agrotóxicos é imanente, não há como impedir a toxicidade, quando muito, possível atenuar os seus efeitos, neste aspecto, se o empregador (usuário) opta pelo uso e não elimina ou neutraliza os efeitos da- nosos da substância, responde objetivamente pelos danos causados (intoxicações agudas ou crônicas).

${ }^{15}$ O Enunciado $n^{\circ} 30$ do Centro de Estudos Judiciários do Conselho da Justiça Federal dispõe: “A responsabilida- de fundada no risco da atividade, como prevista na segunda parte do parágrafo único do art. 927 do novo Código Civil, configura-se quando a atividade normalmente desenvolvida pelo autor do dano causar a pessoa determina- da um ônus maior do que aos demais membros da coletividade".
} 
tolerância da Portaria MTE $n^{\circ}$ 3.214/78. Insista-se, porém, que, mesmo quando tolerados, tais riscos atraem a responsabilidade civil objetiva de seus criadores (art. 927, parágrafo único, do NCC), se traduzem uma situação de risco especialmente grave em relação aos demais cidadãos do mesmo microssistema social.

A subsunção da questão do trabalho com agrotóxicos ao artigo 927, parágrafo único, do Código Civil, é uma das vias hermenêuticas possíveis, sendo que a aplicação do artigo 14, parágrafo $1^{\circ}$, da Lei $\mathrm{n}^{\circ} 6.938 / 81$, que responsabiliza o poluidor a indenizar ou reparar os danos pelas atividades degradantes do meio ambiente, nele incluído o do trabalho, também configura uma hipótese de incidência aplicável ao empregador que submeter os trabalhadores (em especial, os rurais) ao risco natural e sistêmico advindo do uso dos agrotóxicos.

Da mesma forma que não há dúvida sobre o risco agravado inerente aos agrotóxicos, não resta dúvida que a atividade daquele que se vale das substâncias venenosas causa poluição ambiental.

$\mathrm{O}$ artigo $3^{\circ}$, incisos III e IV, da Lei $n^{\circ} 6.938 / 81$, é importantíssimo para entender os contornos da responsabilidade civil em razão da utilização de agrotóxicos, uma vez que conceitua o que é poluição e quais atividades a causam, bem como conceitua dogmaticamente quem deva ser considerado poluidor.

Para os fins previstos na Lei, entende-se por poluição, a degradação da qualidade ambiental resultante de atividades que direta ou indiretamente: a) prejudiquem a saúde, a segurança e o bem-estar da população; b) criem condições adversas às atividades sociais e econômicas; c) afetem desfavoravelmente a biota; d) afetem as condições estéticas ou sanitárias do meio ambiente; e) lancem matérias ou energia em desacordo com os padrões ambientais estabelecidos.

Poluidor é a pessoa física ou jurídica, de direito público ou privado, responsável, direta ou indiretamente, por atividade causadora de degradação ambiental.

Ante o exposto, verifica-se que há uma relação causal direta entre os males descritos nas letras "a" a "e" do artigo $3^{\circ}$ e os agrotóxicos. Portanto, não há como classificar os riscos advindos da manipulação dos agrotóxicos como toleráveis e típicos de uma sociedade de riscos.

A evidência dos malefícios dos agrotóxicos se dá em razão da toxicidade causada por estas substâncias. No caso dos trabalhadores que as manipulam, o empregador tem o dever legal de protegê-los, mediante a adoção de medidas escalonadas de controle e prevenção de riscos, a começar pela eliminação da toxicidade ou neutralização dos efeitos tóxicos, passando por 
medidas de proteção coletiva e finalmente utilização de equipamentos de proteção individual.

É muito comum, notadamente no meio rural, a inexistência de medidas de controle e prevenção de riscos focadas no meio ambiente do trabalho, o que contribui para a maximização do risco (que já é agravado) decorrente do uso de agrotóxicos. O local de trabalho inseguro funciona como uma fonte de riscos sistêmicos, o que empiricamente se observa nas frentes rurais de trabalho em que se manipulam e aplicam os agrotóxicos.

Com base nestas premissas, pode-se dizer que nos acidentes de trabalho ocorridos em virtude da manipulação de agrotóxicos não cabe a aplicação do artigo $7^{\circ}$, inciso XXVIII, da Constituição da República, que exige a comprovação do dolo ou da culpa do empregador para fim de responsabilização.

Seja porque o risco oriundo da atividade é agravado, seja porque a atividade é causadora de poluição ambiental, basta ao trabalhador a comprovação do nexo causal entre a conduta e o dano, o que já é uma tarefa ingrata em vista da dificuldade no estabelecimento do nexo entre a atividade de manipulação de agrotóxicos e as intoxicações crônicas. Nestes casos de intoxicações crônicas, apropriada a inversão do ônus da prova nos processos judiciais de discussão da responsabilidade civil do empregador (PISTORI et al., 2011, p. 40-41).

Portanto, vê-se com tranquilidade a superação da antinomia entre o artigo $7^{\circ}$, XXVIII, da CF, e o artigo 225, par. $3^{\circ}$, da CF (c/c os artigos 927, parágrafo único, do Código Civil e artigo 14 , par. $1^{\circ}$, da Lei 6.938/81), com a aplicação da responsabilidade objetiva na hipótese de acidentes de trabalho causados em razão da atividade de manipulação de agrotóxicos. É o que conclui Guilherme Guimarães Feliciano (2011, p. 301-302):

No entanto, além desses limites ou critérios de tolerância (que podem ser quantitativos ou qualitativos), o risco incrementado passa a caracterizar poluição no meio ambiente de trabalho. Lida-se, nesse caso, com um interesse metaindividual, porque a potencialização dos riscos pela poluição labor-ambiental passa a ameaçar potencialmente os bens mais valiosos de todos os trabalhadores que trabalhem ou possam vir a trabalhar naquele ambiente (em especial a vida e a saúde). Tratando-se, pois, de interesse metaindividual, legitima-se para a ação o Ministério Público do Trabalho, com espeque no que dita o art. 14 , par. $1^{\circ}$, da Lei ${ }^{\circ}$ 6.938/1981 (sem prejuízo da legitimidade processual dos sindicatos e dos próprios trabalhadores prejudicados, individual ou coletivamente considerados). E, consoante a mesma norma, havendo danos ao meio ambiente ou a "terceiros" (como são os trabalhadores) que se atrelem à poluição labor- ambiental por alguma sorte de nexo causal (puramente etiológico ou mesmo concausal), o poluidor - em geral o empregador - é obrigado a repará-los ou indenizá-los, independentemente de culpa (= responsabilidade civil objetiva). Observe- 


\begin{abstract}
se, assim, que a norma em questão vincula a responsabilidade objetiva à poluição, não ao mero risco ambiental (como há, e.g., na atividade de qualquer indústria química, ainda que não polua em absoluto, transformando seus rejeitos em vertidos inertes). (...). Nesses termos, pode-se distinguir, nos lindes da infortunística do trabalho, os danos decorrentes de causalidade sistêmica (que representam a concreção de um quadro de desequilíbrio na disposição ou na combinação dos fatores de produção, i.e., da poluição labor-ambiental) e os danos decorrentes de causalidade tópica (i.e, sem relação com algum desequilíbrio sistêmico do meio ambiente do trabalho). No primeiro caso, a responsabilidade civil patronal rege-se pela norma do art. 14, par. $1^{\circ}$, da Lei ${ }^{\circ}$ 6.938/1981). No segundo caso, a responsabilidade civil patronal rege-se pela norma do art. $7^{\circ}$, XXVIII, da CRFB).
\end{abstract}

Tanto se compreendida a atividade como de risco agravado, como no caso de existência de um ambiente degradado e poluído, impõe-se a responsabilidade objetiva.

\title{
5. CONCLUSÃO
}

O propósito de equacionar a problemática dos agrotóxicos, com vista a uma solução definitiva e realmente inovadora, passa pela conscientização da necessidade de todos os envolvidos conhecerem as facetas de uma questão complexa e dinâmica e agirem para alterar paradigmas.

As ferramentas existentes na legislação sobre saúde e segurança do trabalho em face dos agrotóxicos ganham importância e podem ser decisivas na esperança de reversão do quadro caótico existente, desde que haja correta compreensão da questão, tanto em relação aos elementos jurídicos, como em relação aos elementos extrajurídicos que a permeiam.

Somente ações e medidas que contem com a ampla participação e mobilização da sociedade civil e uma postura do Poder Judiciário que efetivamente considere a higidez do meio ambiente do trabalho um direito fundamental e um sobrevalor podem representar solução inovadora capaz de mudar os paradigmas.

Qualquer solução jurídica a ser apontada deve ir ao encontro de uma visão multidisciplinar dos fatores envolvidos. A solução ideal seria a eliminação dos agrotóxicos, com o desenvolvimento de meios alternativos de combate às pragas agrícolas, o que parece utópico, haja vista a realidade da indústria produtora de agrotóxicos, a ordenação do território agrícola e a predominância das monoculturas no mundo contemporâneo, cada vez mais ameaçado pelas mudanças climáticas e pela escassez de alimentos.

No que tange à proteção dos trabalhadores, ineficazes os mecanismos de controle de riscos postos pela legislação para impedir o registro de agrotóxicos e a introdução das 
substâncias contaminantes no mercado, cabe exigir do empregador a adoção de medidas que impliquem a substituição de substâncias mais tóxicas por menos tóxicas e a priorização de medidas protetivas coletivas no ambiente de trabalho, em suma, o desenvolvimento de técnicas e métodos que diminuam o nível de exposição dos trabalhadores às substâncias tóxicas.

Partindo da premissa de que mesmo que implementadas tais medidas é impossível eliminar ou ter certeza sobre a segurança quanto aos níveis de exposição, há que estabelecer a responsabilidade civil objetiva do empregador pelos danos causados na manipulação de agrotóxicos pelos trabalhadores, seja porque decorre de risco agravado e inerente à própria atividade, seja porque há risco sistêmico oriundo de uma atividade notoriamente poluidora.

\section{REFERÊNCIAS BIBLIOGRÁFICAS}

CONTE, Ana Carolina Papacosta; SOARES, Inês Virgínia Prado. Registro de agrotóxicos e controle social. Boletim Científico ESMPU, Brasília, v. 1, n. 1, p. 9-22, out./dez. 2001.

ESPÍNDOLA, Évellyn Aparecida. Análise da percepção de risco do uso de agrotóxicos em áreas rurais: um estudo junto aos agricultores no município de Bom Repouso (MG). 2011. Tese (Doutorado em Ciências da Engenharia Ambiental) - Faculdade de Engenharia de São Carlos, Universidade de São Paulo, São Carlos, 2011.

FALCÃO JÚNIOR, Alfredo Carlos Gonzaga. Agrotóxicos e responsabilidade criminal. Revista dos Tribunais, São Paulo, v. 98, n. 869, p. 461-79, nov. 2009.

FELICIANO, Guilherme Guimarães. Saúde e segurança no trabalho: o meio ambiente do trabalho e a responsabilidade civil patronal. In: THOME, Candy Florencio, SCHWARZ, Rodrigo Garcia. (Org.). Direito individual do trabalho: curso de revisão e atualização. São Paulo: Elsevier, 2011. p. 287-306.

. Sobre a competência da Justiça do Trabalho para causas de Direito Administrativo sancionador. Jus Navigandi, Teresina, ano 10, n. 688, 24 maio 2005. Disponível em: <http://jus.com.br/revista/texto/6755>. Acesso: 15 ago. 2012.

Teoria da imputação objetiva no direito penal ambiental brasileiro. São Paulo: LTr, 2005. 
GARCIA, Eduardo Garcia. Segurança e saúde no trabalho rural: a questão dos agrotóxicos. São Paulo: FUNDACENTRO, 2001. 182 p.

; ALVES FILHO, José Prado. Aspectos de prevenção e controle de acidentes no trabalho com agrotóxicos. São Paulo: FUNDACENTRO, 2005. 52 p.

LONDRES, Flavia. Agrotóxicos no Brasil: um guia para ação em defesa da vida. Rio de Janeiro: ASPTA - Assessoria e Serviços a Projetos em Agricultura Alternativa, 2011.

LOPES, Maria Elizabete Barretto de Menezes. Agrotóxicos na imprensa: análise de revistas e jornais brasileiros. 2010. Tese (Doutorado em Ecologia Aplicada) - Escola Superior de Agricultura Luiz de Queiroz, Universidade de São Paulo, Piracicaba, 2010.

MACHADO, Paulo Affonso Leme. Direito ambiental brasileiro. 20. ed. São Paulo: Malheiros Ed., 2012.

OLIVEIRA, Sebastião Geraldo de. Proteção jurídica à saúde do trabalhador. 6. ed. São Paulo: LTr, 2011.

OLIVEIRA, Sérgia de Souza. O papel da avaliação de riscos no gerenciamento de produtos agrotóxicos: diretrizes para a formação de políticas públicas. 2005. Tese (Doutorado) Programa de Pós-Graduação em Saúde Pública - Faculdade de Saúde Pública, Universidade de São Paulo para obtenção do título de Doutor em Saúde Pública, São Paulo, 2005.

PISTORI, Gerson Lacerda; SOUTO MAIOR, Jorge Luiz; TOLEDO FILHO, Manoel Carlos; FELICIANO, Guilherme Guimarães (Orgs.). Fênix: por um novo processo do trabalho. São Paulo: LTr, 2011.

RIOS, Aurélio Virgílio Veiga. O Mercosul, os agrotóxicos e o princípio da precaução., Revista de Direitos Difusos, São Paulo, v. 2, n. 13, p. 1677-1691, jun. 2002.

SOARES, Evanna. Ação ambiental trabalhista: uma proposta de defesa judicial do direito humano ao meio ambiente do trabalho no Brasil. Porto Alegre: Sergio Antonio Fabris Ed., 2004. 
VAZ, Paulo Afonso Brum. Agrotóxicos e meio ambiente. Boletim dos Procuradores da República, São Paulo, v. 4, n. 43, p. 16-28, nov. 2001. 